\title{
Short communication: Grazing pattern of dairy cows that were selected for divergent residual feed intake as calves
}

\author{
P. Gregorini, ${ }^{1}$ G. C. Waghorn, B. Kuhn-Sherlock, A. J. Romera, and K. A. Macdonald \\ DairyNZ, Private Bag 3221, Hamilton 3240, New Zealand
}

\section{ABSTRACT}

The aim of this study was to investigate and assess differences in the grazing pattern of 2 groups of mature dairy cows selected as calves for divergent residual feed intake (RFI). Sixteen Holstein-Friesian cows (471 $\pm 31 \mathrm{~kg}$ of body weight, $100 \mathrm{~d}$ in milk), comprising 8 cows selected as calves (6-8 mo old) for low (most efficient: $\mathrm{CSC}_{\text {LowRFI }}$ ) and 8 cows selected as calves for high (least efficient: $\mathrm{CSC}_{\mathrm{HighRF}}$ ) RFI, were used for the purpose of this study. Cows $(\mathrm{n}=16)$ were managed as a single group, and strip-grazed (24-h pasture allocation at $0800 \mathrm{~h}$ ) a perennial ryegrass sward for 31 $\mathrm{d}$, with measurements taken during the last $21 \mathrm{~d}$. All cows were equipped with motion sensors for the duration of the study, and jaw movements were measured for three 24-h periods during 3 random nonconsecutive days. Measurements included number of steps and jaw movements during grazing and rumination, plus fecal particle size distribution. Jaw movements were analyzed to identify bites, mastication (oral processing of ingesta) during grazing bouts, chewing during rumination, and to calculate grazing and rumination times for 24 -h periods. Grazing and walking behavior were also analyzed in relation to the first meal of the day after the new pasture was allocated. Measured variables were subjected to multivariate analysis. Cows selected for low RFI as calves appeared to (a) prioritize grazing and rumination over idling; (b) take fewer steps, but with a higher proportion of grazing steps at the expense of nongrazing steps; and (c) increase the duration of the first meal and commenced their second meal earlier than $\mathrm{CSC}_{\text {HighRFI }}$. The $\mathrm{CSC}_{\text {LowRFI }}$ had fewer jaw movements during eating $\left(39,820\right.$ vs. 45,118 for $\mathrm{CSC}_{\text {LowRFI }}$ and $\mathrm{CSC}_{\mathrm{HighRFI}}$, respectively), more intense rumination (i.e., 5 more chews per bolus), and their feces had $30 \%$ less large particles than $\mathrm{CSC}_{\mathrm{HighRFI}}$. These results suggest that $\mathrm{CSC}_{\text {LowRFI }}$ concentrate their grazing activity to the time when fresh pasture is allocated, and graze

Received March 23, 2015.

Accepted June 9, 2015.

${ }^{1}$ Corresponding author: Pablo.Gregorini@dairynz.co.nz more efficiently by walking and masticating less, hence they are more efficient grazers than $\mathrm{CSC}_{\mathrm{HighRFI}}$.

Key words: dairy cow, residual feed intake, grazing behavior

\section{Short Communication}

Over the last $50 \mathrm{yr}$, cattle have been selected intensively for a diverse combination of output characteristics (e.g., milk production, growth rate), but rarely for feed intake or foraging behavior (Emmans and Kyriazakis, 2001). However, because of the importance of the efficiency with which cattle convert feed to product, interest and research in genetic selection for improved feed conversion efficiency and residual feed intake (RFI) has been increasing. Animals with low RFI are considered to have better feed conversion efficiency than animals with high RFI. Residual feed intake is defined as the difference between actual feed intake and that predicted on the basis of production and maintenance requirements. This interest has led to the evaluation and characterization of RFI in calves during growth (Waghorn et al., 2012) and in cows during lactation (Macdonald et al., 2014). An analysis of calf feeding behavior during selection for RFI has been undertaken (Green et al., 2013), and gene expression and heritability has been demonstrated in New Zealand dairy cattle (Davis et al., 2014). Animals vary in their behavior and efficiency for production, but measurement of RFI and identification of divergence (Waghorn et al., 2012) must be conducted under confined feeding environments. Such a feeding environment is substantially different from grazed pastures, where divergences in RFI between individuals in New Zealand have evolved.

Evidence indicates that Holstein-Friesian calves selected for divergence in RFI during growth exhibited significant RFI divergence (although reduced) in their first lactation (Macdonald et al., 2014) and that variations in RFI are heritable (Pryce et al., 2012). This suggests that some genetic regulation of differences in the behavior of divergent individuals, which has been evident during the selection of calves (Green et al., 2013), may also affect other traits. Grazing pattern and efficiency were the focus traits of the present study. 
Grazing is an arrangement of ingestive actions nested in time and spatial scales (Senft et al., 1987), and its efficiency relates to trade-offs that define short-term behavioral strategies (from a bite to a meal) as the means by which animals maximize acquire nutrients (Bergman et al., 2001; Owen-Smith et al., 2010) and meet their energy requirements (Emmans and Kyriazakis, 2001). Behavioral patterns (e.g., grazing) comprise suites of correlated behavioral traits, reflecting individual consistency in behavior (Sih and Bell, 2008); therefore, grazing patterns cannot be studied by assessing individual behavioral traits in isolation.

Whereas recent research on divergent RFI has focused on physiology and nutrition, grazing pattern and its potential explanatory function in this divergence has been ignored. Thus, the aim of the present study was to describe behavioral differences in the grazing pattern of mature dairy cows selected as calves for either low or high RFI.

The study was conducted at Lye Farm at DairyNZ during October and November 2012 and was approved by the Ruakura Animal Ethics Committee (AE Application 12744). The 16 Holstein-Friesian cows used in our study comprised 8 selected as calves for low RFI ( $\left.\mathbf{C S C}_{\text {LowRFI }}\right)$ and 8 selected as calves for high RFI $\left(\mathbf{C S C}_{\text {HighRFI }}\right)$ from the extremes of 440 calves (6-8 mo of age) evaluated for RFI (Waghorn et al., 2012). During the selection process for divergent RFI, the average calf DMI was $7.5 \mathrm{~kg}$ with the calves with low RFI averaging -1.06 (range $=-0.73$ to -1.32 ) and the calves with high RFI averaged $0.70 \mathrm{~kg}$ (range $=0.58$ to 0.94$)$. The difference between the 2 groups of calves selected for this study was $23.4 \%(-14.1$ and $9.3 \%$, respectively). Cows in each group were $100 \pm 10$ DIM and weighed $496 \pm 31\left(\mathrm{CSC}_{\text {LowRFI }}\right)$ and $505 \pm 43$ $\mathrm{kg}\left(\mathrm{CSC}_{\text {HighRFI }}\right)$.

The 2 groups of cows strip-grazed (24-h pasture allocation at $0800 \mathrm{~h}$ ) a Lolium perenne L. sward as a common herd for $31 \mathrm{~d}$. Herbage allowance was $30 \mathrm{~kg}$ of DM/cow per day to ground level. The first $10 \mathrm{~d}$ were used to adapt the cows to the measurement devices, and the remaining $21 \mathrm{~d}$ for measurements. The cows had ad libitum access to fresh water at pasture and were milked at 0700 and $1500 \mathrm{~h}$. Milk yield and composition, BW, and BCS (10-point scale, where 1 is emaciated and 10 is obese; Roche et al., 2004) were determined weekly.

Each cow had an IceTag 3D motion sensor (Ice Robotics, Ltd., Edinburgh, UK) attached to her left hind leg for the duration of the study. This device recorded the number of steps taken each minute, as well as the frequency and duration of lying periods. Jaw movements were recorded in all cows for 3 random, nonconsecutive 24-h periods. Jaw movement recorders (Ultra
Sound Advice, London, UK) were fitted immediately after morning milking. Jaw movements were analyzed using GRAZE software (Rutter, 2000) to identify bites, mastications (oral processing of ingesta; i.e., movements during ingestion), chews during rumination and grazing, and rumination bouts; GRAZE also provided grazing, rumination and idling times. Grazing steps were identified by combining step data from the IceTag $3 \mathrm{D}$ sensors with the jaw-movement recordings, and only counting steps when cows were grazing. Nongrazing steps taken by the cows were calculated by subtracting grazing steps from total steps.

Measured and calculated variables are presented as the sum for the whole $24 \mathrm{~h}$ (daily data), and also the sums for 3 distinct periods during the day (diurnal data): morning ( $\sim 0700-1500 \mathrm{~h}$, from morning to afternoon milking), afternoon (from afternoon milking to darkness, 1500-2030 h), and night (from darkness to morning milking, 2030-0700 h). Darkness was defined as the end of dusk using nautical twilight. In addition, some of the measured and calculated variables of ingestive and walking behavior are presented for the first meal of the day, after the new pasture was allocated, as well as the length of the first meal and the delay between the first and second meal of the day. Meal was defined as a cluster of prehension bouts delimited by rumination or idling bouts.

Fecal samples for particle size distribution analysis were taken from each cow at the end of each $24 \mathrm{~h}$ jaw movement recording. Two sieves, $100 \mathrm{~mm}$ in diameter with holes of 2 and $1 \mathrm{~mm}$ in size (length of square side) were used to wash the feces and to retain particulate material. Retained particles were weighed and dried for $72 \mathrm{~h}$ at $60^{\circ} \mathrm{C}$. When dry, the DM of the particles of different sizes was determined and expressed as percentage of total fecal DM.

Pregrazing herbage mass from pasture strips was estimated using the rising plate meter (Farmworks, Palmerston North, New Zealand) to calculate herbage allowance and pasture strip size. Pregrazing herbage mass averaged $3,074 \pm 252 \mathrm{~kg}$ of DM/ha. Herbage contained $160 \pm 40 \mathrm{~g} / \mathrm{kg}$ of DM of CP, $520 \pm 68 \mathrm{~g} / \mathrm{kg}$ of $\mathrm{DM}$ of NDF, and a predicted OMD of $770 \pm 90 \mathrm{~g} / \mathrm{kg}$ of DM.

For descriptive purposes, measured and calculated variables were analyzed individually (univariate ANOVA) using mixed models approach to repeated measures ANOVA (Proc Mixed, SAS 9.3, SAS Institute Inc., Cary, NC). The model for daily data included group $\left(\mathrm{CSC}_{\text {LowRFI }}\right.$ and $\left.\mathrm{CSC}_{\mathrm{HighRFI}}\right)$, measurement day (first, second, or third 24-h period), their interaction, and the jaw-movement recorder as fixed effects, as well as cow as random effect. The model for diurnal data included the same factors as the daily model, with the addition 
of time of day (morning, afternoon, or night) and its interactions. Milk production and composition, BW, and changes in BCS were analyzed individually (univariate ANOVA) with group $\left(\mathrm{CSC}_{\mathrm{LowRFI}}\right.$ and $\left.\mathrm{CSC}_{\mathrm{HighRFI}}\right)$ as the treatments.

To distinguish grazing patterns, behavior variables were investigated in combination with each other. This required multivariate analyses, in particular multivariate analysis of variance and canonical variate analysis (MANOVA and CVA, Proc Candisc, SAS 9.3). The Wilk's Lambda multivariate test (MANOVA) was used to determine if a difference $(P<0.05)$ existed between the $\mathrm{CSC}_{\mathrm{LowRFI}}$ and $\mathrm{CSC}_{\mathrm{HighRFI}}$ when considering all variables simultaneously. The pooled within-class standardized canonical coefficients (CC) were used to calculate a new variable, the canonical variate, as a weighted linear combination of the discriminating variables that maximizes the difference between groups. The canonical coefficients are standardized using the within-group covariance matrix, to allow comparing variables measured on different scales. The CC determine which combination of variables contributed most to the separation between groups in a multivariate sense. Coefficients with large absolute values correspond to variables with greater discriminating ability. The variables included in the analysis of daily data were: time (attributed to grazing, rumination, and idling), lying (total minutes and lying frequency), bouts (total number and numbers attributed to eating and rumination), jaw movements (total number and numbers attributed to mastication, chewing, and prehension), rumination boli, steps (total number and numbers attributed to grazing and other), fecal DM, and fecal particle size distribution (percent of large, medium, and small). The variables included in the analysis of diurnal data (morning, afternoon and night) were the same as the daily variables except for fecal particle size distribution that was not included. For the analysis of behavior during the first meal, the variables included were meal duration and delay between first and second meal, jaw movements (total number and number attributed to mastication and prehension), and steps (total number and number attributed to grazing).

Mean values of grazing, rumination, and idling time $(600,496$, and $306 \mathrm{~min} / \mathrm{d}$, respectively) for the 2 groups of cows in the present study fell within the ranges reported in a meta-analysis by Pérez-Prieto and Delagarde (2012) for grazing dairy cows with similar characteristic and grazed in similar environments to the one for the present study.

The univariate analyses highlighted some differences in foraging behavior between $\mathrm{CSC}_{\text {LowRFI }}$ and $\mathrm{CSC}_{\mathrm{HighRFI}}$. Over $24 \mathrm{~h}, \mathrm{CSC}_{\text {LowRF }}$ tended to take $14 \%$ fewer steps than $\mathrm{CSC}_{\text {HighRFI }}$ cows $(3,311$ vs. 3,$880 ; P=0.06)$, and the number of grazing steps was $23 \%$ lower (1,797 vs.
$2,323$ steps; $P=0.04)$. The $\mathrm{CSC}_{\mathrm{LowRF}}$, also tended to take more bites $(38,870$ vs. 35,$365 ; P<0.10)$, but masticated $54 \%$ less $(4,360$ vs. 9,450 mastication jaw movements; $P<0.001)$. The first meal was $18 \%$ shorter for $\mathrm{CSC}_{\text {LowRFI }}(178$ vs. $218 \mathrm{~min} ; P<0.10)$, they took $39 \%$ fewer grazing steps (520 vs. $856 ; P=0.03$ ), and tended to have a shorter delay between the first and second meal compared with $\mathrm{CSC}_{\mathrm{HighRFI}}(38$ vs. $50 \mathrm{~min} ; P=$ $0.10)$. The univariate analyses, however, did not detect significant differences in milk production and composition (fat, protein, and lactose), BW gain, and changes in $\mathrm{BCS}$ between $\mathrm{CSC}_{\mathrm{LowRFI}}$ and $\mathrm{CSC}_{\mathrm{HighRFI}}$, averaging $24.6 \mathrm{~L} / \mathrm{d}, 4.36 \%, 3.44 \%, 4.85 \%, 0.56 \mathrm{~kg} / \mathrm{d}$, and -0.4 points, respectively.

Combining all daily variables demonstrated a highly significant difference between the $\mathrm{CSC}_{\text {LowRFI }}$ and $\mathrm{CSC}_{\text {HighRFI }}$ (MANOVA $P=0.002$ ). The canonical variate, which accounted for $84 \%( \pm 4.7 \%)$ of the between-group variation, is presented in Table 1 . The $\mathrm{CC}$ indicate that the variables with the largest weight in separating between the groups are grazing time, masticatory jaw movements, total steps, and grazing steps, followed by rumination time.

Multivariate analyses demonstrated significant differences between the groups of cows in the morning and afternoon (MANOVA $P<0.05$ ), and also for the first meal (MANOVA $P<0.01$ ). No significant difference was detected at night. The canonical variate explained $79( \pm 5.8), 69( \pm 8.3)$, and $62 \%( \pm 9.5 \%)$ of the betweengroup variation for morning, afternoon, and first meal, respectively (Table 1). The most important variables separating the groups in the morning were prehensile and masticatory jaw movements, as well as total steps. Separation in the afternoon was driven by total versus prehensile and masticatory jaw movements, whereas jaw movements and grazing steps were important for the first meal.

Behavioral correlations involve trade-offs, for example in time budgeting. As the amount of available time is fixed, the more time invested in one activity, the less time available for another. Cows cannot ruminate or idle while they are grazing, and vice versa. Although these activities are important, it is impossible for an animal to maximize each. Thus, an adaptive trade-off on demands for grazing, ruminating, and idling is necessary. The values of the $\mathrm{CC}$ (Table 1) indicate that grazing and rumination times were more important separators between the 2 groups of cows than idling time, and both were higher in $\mathrm{CSC}_{\text {LowRFI }}$ than $\mathrm{CSC}_{\text {HighRFI }}$. The difference in the canonical variate between groups suggests that, compared with $\mathrm{CSC}_{\text {HighRFI }}, \mathrm{CSC}_{\text {LowRFI }}$ prioritized grazing and rumination over idling. Also, $\mathrm{CSC}_{\text {LowRFI }}$ seem to combine longer grazing time with fewer steps and take more grazing steps at the expense 
Table 1. Daily and diurnal canonical variate and coefficients (CC) for behavioral variables and fecal particle size distribution of cows selected as calves for low $\left(\mathrm{CSC}_{\mathrm{LowRFI}}\right)$ and high $\left(\mathrm{CSC}_{\mathrm{HighRFI}}\right) \mathrm{RFI}$ grazing a Lolium perenne L.-based sward (the greater the absolute value of the canonical coefficients, the more important the variable is in explaining the variation)

\begin{tabular}{|c|c|c|c|c|}
\hline \multirow[b]{2}{*}{ Variable } & \multicolumn{4}{|c|}{ Canonical coefficients } \\
\hline & Daily $^{1}$ & First meal $^{2}$ & Morning $^{3}$ & Afternoon $^{4}$ \\
\hline Grazing time & -1.41 & & -0.74 & 0.13 \\
\hline Rumination time & -0.94 & & 0.79 & 2.64 \\
\hline Idling time & -0.55 & & & \\
\hline Total steps & 1.25 & & 1.14 & -0.06 \\
\hline Grazing steps & -1.12 & & -0.61 & 0.46 \\
\hline Laying time & 0.05 & & 0.43 & -0.25 \\
\hline Laying bouts & -0.36 & & -0.32 & -0.35 \\
\hline Total jaw movements & 0.27 & & -0.79 & -6.07 \\
\hline Prehensile jaw movements & 0.59 & & 1.43 & 4.73 \\
\hline Masticatory jaw movements & 1.29 & & 1.50 & 3.25 \\
\hline Fecal DM & -0.96 & & & \\
\hline Fecal particles $1-2 \mathrm{~mm}$ & 0.74 & & & \\
\hline Fecal particles $>2 \mathrm{~mm}$ & 0.35 & & & \\
\hline Eating bouts & -0.46 & & -0.73 & -0.26 \\
\hline Rumination bouts & 0.11 & & & \\
\hline Rumination boli & -0.18 & & -0.52 & 0.90 \\
\hline Length of the first meal & & -0.94 & & \\
\hline Interval between the first and second meal & & 0.32 & & \\
\hline Grazing steps in the first meal & & 1.05 & & \\
\hline Total jaw movements in the first meal & & 1.70 & & \\
\hline Prehensile jaw movements in the first meal & & -1.21 & & \\
\hline Masticatory jaw movements in the first meal & & 0.00 & & \\
\hline \multicolumn{5}{|l|}{ Canonical variates } \\
\hline $\mathrm{CSC}_{\text {LowRFI }}$ & -1.36 & -0.69 & -1.15 & -0.83 \\
\hline $\mathrm{CSC}_{\mathrm{HighRFI}}$ & 1.65 & 0.83 & 1.40 & 1.01 \\
\hline$P$-value & 0.001 & 0.002 & $<0.001$ & 0.04 \\
\hline
\end{tabular}

${ }^{1}$ Sum for the whole $24 \mathrm{~h}$.

${ }^{2}$ From the time the new pasture was allocated $(0800 \mathrm{~h})$ to the end of the meal (meal is defined as a cluster of prehension bouts delimited by rumination or idling bouts) as well as the interval between the first and second meal of the day.

${ }^{3} 0700-1500 \mathrm{~h}$ (from morning to afternoon milking).

${ }^{4} 1500-2030 \mathrm{~h}$ (from afternoon milking to darkness).

of nongrazing steps (Table1). Although ruminants digest during idling, the animal could instead be acquiring energy (grazing) or actively taking other actions, such as rumination, to evacuate the rumen. Behavioral trade-offs play a major role in adaptive behavior (Sih et al., 2004). Thus, the multivariate analysis revealed that, at a daily level, $\mathrm{CSC}_{\text {LowRFI }}$ are better adapted to grazing, as they appear to concentrate more effort (time and steps) toward acquiring nutrients and energy.

The largest proportion of the daily herbage DMI in grazing dairy cows happens during the first few hours $(3-4 \mathrm{~h})$ after new pasture is allocated (Gregorini et al., 2009a). The length of the first meal (198 min) for $\mathrm{CSC}_{\text {LowRFI }}$ and $\mathrm{CSC}_{\mathrm{HighRFI}}$ fell within ranges reported in the literature (Soca et al., 2014; Chilibroste et al., 2015). Compared with $\mathrm{CSC}_{\text {HighRFI }}, \mathrm{CSC}_{\text {LowRFI }}$ had a shorter first meal, but this meal represented a larger proportion of the total morning grazing time and the interval between the first and second meal was shorter. This suggests that $\mathrm{CSC}_{\mathrm{LowRFI}}$ spend a greater propor- tion of time grazing (instead of idling) and increase meal frequency at the time of the day when the herbage is still relatively undisturbed. Undisturbed sward canopies allow for greater herbage intake rates. Grazing ruminants under the strip-grazing method consume the herbage in successive layers of the canopy. By concentrating grazing activity in the morning, the distribution of grazing time and meal frequency employed by CS$\mathrm{C}_{\text {LowRFI }}$ is conducive to harvesting herbage more easily and acquiring more leaves, which is important because leaves have the highest feeding value (Gregorini et al., 2009b). This point is further supported by the fact that, relative to $\mathrm{CSC}_{\mathrm{HighRFI}}, \mathrm{CSC}_{\mathrm{LowRFI}}$ laid down less in the morning and had a greater lying frequency and longer lying time during the rest of the day when less herbage was available. Overall, these differences in time allocation support the argument that $\mathrm{CSC}_{\mathrm{LowRFI}}$ seem to budget time better in adapting to strip-grazing.

Differences were also noted between groups in behavioral actions during grazing. Relative to $\mathrm{CSC}_{\mathrm{HighRFI}}$, 
$\mathrm{CSC}_{\text {LowRFI }}$ took fewer total steps, but increased the proportion of grazing steps at the expense of steps for other activities. The $\mathrm{CSC}_{\text {LowRFI }}$ also made fewer jaw movements and greatly reduced the proportion of jaw movements attributed to mastication, hence increasing chewing jaw movements during rumination. During the first meal of the day, $\mathrm{CSC}_{\text {LowRFI }}$ cows took fewer grazing steps but more bites compared with $\mathrm{CSC}_{\mathrm{HighRFI}}$. In summary, $\mathrm{CSC}_{\text {LowRFI }}$ not only walked less, but when they did they grazed instead of wandering around and during the first and most important meal of the day they walked even less, took more bites, and masticated significantly less.

The feeding station is the area of pasture an animal can reach with each grazing step, and decisions regarding the profitability of each bite (harvested digestible energy per unit of handling time) influence the residence time per feeding station (Searle et al., 2005). As the more profitable bites from a feeding station are removed, the profitability of the feeding station begins to decline. This decline and the perception of more profitable feeding stations in the surrounding areas motivates the animal to move to a new feeding station (Wade and Gregorini, 2010). The results indicate that $\mathrm{CSC}_{\mathrm{LowRFI}}$ seem to perceive profitability of feeding stations, and thereby the grazing environment, differently from $\mathrm{CSC}_{\mathrm{HighRFI}}$. Owen-Smith et al. (2010) define grazing efficiency as the ratio between grazing and walking time, which is enhanced by increments short-term herbage intake rates (at the expense of mastication) and increased residence time per feeding station (Gregorini et al., 2009b). Thus, the results presented here (e.g., less walking and more grazing during the first meal) indicate that $\mathrm{CSC}_{\mathrm{LowRF}}$ had a greater foraging performance and are more efficient grazers.

Over the course of a day, the $\mathrm{CSC}_{\text {LowRFI }}$ took approximately $14 \%$ less steps and masticated half as much compared with the $\mathrm{CSC}_{\text {HighRFI}}$. At a constant energy cost of walking and assuming the cost of mastication is 3 times that of biting (Wright and Illius, 1995), these results suggest that $\mathrm{CSC}_{\text {LowRFI }}$ may spend less energy during grazing. Moreover, while grazing, $\mathrm{CSC}_{\text {LowRFI }}$ walked more slowly than $\mathrm{CSC}_{\mathrm{HighRF}}$, both at the daily level (1.3 versus $1.6 \mathrm{steps} / \mathrm{min}$ of grazing, $P=0.04$ ) and during the first meal (2.8 vs. 3.9 steps/min of grazing, $P=0.05)$. Faster walking while grazing comes at a cost (i.e., energy expenditure), as an animal needs to overcome the inertia of slowing down and stopping to select a bite and then leaving the feeding station more frequently. The animal may, therefore, choose to take more bites at one feeding station (or increase the residence time in it) to make more efficient use of (or save) energy. Energy expenditure associated with activity has been correlated with feed conversion efficiency in cattle
(Richardson et al., 1999). Based on these concepts and the present results, it appears that $\mathrm{CSC}_{\mathrm{LowRF}}$ are energetically more efficient grazers.

The multivariate analysis also indicated that $\mathrm{CSC}_{\text {Low- }}$ RFI and $\mathrm{CSC}_{\mathrm{HighRFI}}$ have different rumination patterns and intensity. Overall, $\mathrm{CSC}_{\text {LowRFI }}$ prioritized daily grazing and rumination times at the expense of idling time. Relative to $\mathrm{CSC}_{\mathrm{HighRFI}}$, however, $\mathrm{CSC}_{\mathrm{LowRFI}}$ decreased rumination during the morning, when sward canopy was still undisturbed. The $\mathrm{CSC}_{\mathrm{LowRFI}}$ performed fewer rumination bouts with a greater number of boli; the latter indicates more intense rumination bouts. This different rumination pattern is reflected in the fecal particle size distribution. Relative to the $\mathrm{CSC}_{\mathrm{HighRF}}$, $\mathrm{CSC}_{\text {LowRFI }}$ excreted feces with a $30 \%$ less large particles. Smaller particle size in feces may be an indication of a greater extent of rumen digestion. This premise is supported by a previous indoor feeding trial by Rius et al. (2012), who reported that cows selected for lower RFI as calves (i.e., $\mathrm{CSC}_{\text {LowRFI }}$ ) tended to attain better digestibility, and Herd and Arthur (2009), who reported that digestibility may contribute approximately $10 \%$ to the difference in RFI of cattle.

In summary, $\mathrm{CSC}_{\text {LowRFI }}$ prioritize grazing and rumination, concentrating grazing during the morning at the time that fresh pasture was allocated and ruminating later in the day and more intensely. While grazing, $\mathrm{CSC}_{\text {LowRFI }}$ walk less and more slowly, masticate less, and take more bites per grazing step (i.e., feeding station). Based on these results it is postulated that animals selected for low RFI early in life (e.g., $\mathrm{CSC}_{\text {LowRFI }}$ ), may develop more efficient grazing patterns as mature animals. The challenge is to identify how to manage more efficient grazers (e.g., $\left.\mathrm{CSC}_{\mathrm{LowRFI}}\right)$ to enhance their strengths or reduce weaknesses of $\mathrm{CSC}_{\mathrm{HighRFI}}$ when grazing.

\section{REFERENCES}

Bergman, C. M., J. M. Fryxell, C. C. Gates, and D. Fortin. 2001. Ungulate foraging strategies: Energy maximizing or time minimizing? J. Anim. Ecol. 70:289-300.

Chilibroste, P., P. Soca, and D. Mattiauda. 2015. Behavioural adaptation of dairy cows to changes in feeding management: Do they follow a predictable pattern or do they adjust their behaviour for each specific treatment? Anim. Prod. Sci. 55:328-338.

Davis, S. R., K. A. Macdonald, G. Waghorn, and R. Spelman. 2014. Residual feed intake of lactating Holstein-Friesian cows predicted from high-density genotypes and phenotyping of growing heifers. J. Dairy Sci. 97:1436-1445.

Emmans, G., and I. Kyriazakis. 2001. Consequences of genetic change in farm animals on food intake and feeding behaviour. Proc. Nutr. Soc. 60:115-125.

Green, T. C., J. Jago, K. A. Macdonald, and G. Waghorn. 2013. Relationships between residual feed intake, average daily gain, and feeding behavior in growing dairy heifers. J. Dairy Sci. 96:30983107.

Gregorini, P., C. Clark, J. Jago, C. Glassey, K. McLeod, and A. Romera. 2009a. Restricting time at pasture: Effects on dairy cow 
herbage intake, foraging behavior, hunger-related hormones, and metabolite concentration during the first grazing session. J. Dairy Sci. 92:4572-4580.

Gregorini, P., S. Gunter, P. Beck, J. Caldwell, M. Bowman, and W. Coblentz. 2009b. Short-term foraging dynamics of cattle grazing swards with different canopy structures. J. Anim. Sci. 87:38173824 .

Herd, R. M., and P. Arthur. 2009. Physiological basis for residual feed intake. J. Anim. Sci. 87(E. Suppl):E64-E71.

Macdonald, K. A., J. Pryce, R. Spelman, S. Davis, W. Wales, G. Waghorn, Y. Williams, L. Marett, and B. Hayes. 2014. HolsteinFriesian calves selected for divergence in residual feed intake during growth exhibited significant but reduced residual feed intake divergence in their first lactation. J. Dairy Sci. 97:1427-1435.

Owen-Smith, N., J. Fryxell, and E. Merrill. 2010. Foraging theory upscaled: The behavioural ecology of herbivore movement. Philos. Trans. R. Soc. Lond. B Biol. Sci. 365:2267-2278.

Pérez-Prieto, L. A., and R. Delagarde. 2012. Meta-analysis of the effect of pregrazing pasture mass on pasture intake, milk production, and grazing behavior of dairy cows strip-grazing temperate grasslands. J. Dairy Sci. 95:5317-5330.

Pryce, J. E., J. Arias, P. Bowman, S. Davis, K. A. Macdonald, G. Waghorn, W. Wales, Y. Williams, R. Spelman, and B. Hayes. 2012. Accuracy of genomic predictions of residual feed intake and 250-day body weight in growing heifers using 625,000 single nucleotide polymorphism markers. J. Dairy Sci. 95:2108-2119.

Richardson, E., R. Kilgour, J. Archer, and R. Herd. 1999. Pedometers measure differences in activity in bulls selected for high or low net feed efficiency. Proc. Aust. Soc. Study Anim. Behav 26:16.

Rius, A. G., S. Kittelmann, K. A. Macdonald, G. Waghorn, P. Janssen, and E. Sikkema. 2012. Nitrogen metabolism and rumen microbial enumeration in lactating cows with divergent residual feed intake fed high-digestibility pasture. J. Dairy Sci. 95:5024-5034.
Roche, J. R., P. Dillon, C. Stockdale, L. Baumgard, and M. VanBaale. 2004. Relationships among international body condition scoring systems. J. Dairy Sci. 87:3076-3079.

Rutter, S. M. 2000. Graze: A program to analyze recordings of the jaw movements of ruminants. Behav. Res. Methods Instrum. Comput. 32:86-92.

Searle, K. R., N. Thompson Hobbs, and L. A. Shipley. 2005. Should I stay or should I go? Patch departure decisions by herbivores at multiple scales. Oikos 111:417-424.

Senft, R., M. Coughenour, D. Bailey, L. Rittenhouse, O. Sala, and D. Swift. 1987b. Large herbivore foraging and ecological hierarchies. Bioscience 37:789-799.

Sih, A., and A. M. Bell. 2008. Insights for behavioral ecology from behavioral syndromes. Adv. Study Behav. 38:227-281.

Sih, A., A. M. Bell, J. C. Johnson, and R. E. Ziemba. 2004. Behavioral syndromes: An integrative overview. Q. Rev. Biol. 79:241-277.

Soca, P., H. González, H. Manterola, M. Bruni, D. Mattiauda, P. Chilibroste, and P. Gregorini. 2014. Effect of restricting time at pasture and concentrate supplementation on herbage intake, grazing behaviour and performance of lactating dairy cows. Livest. Sci. 170:35-42.

Wade, M., and P. Gregorini. 2010. Bite characteristics and grazing dynamics of cattle. Pages 165-176. in Proc. Int. Workshop in Honor to Prof. J. Hodgson, Tandil, Buenos Aires, Argentina. Universidad Nacional del Centro de la Provincia de Buenos Aires, Tandil, Buenos Aires, Argentina.

Waghorn, G. C., K. A. Macdonald, Y. Williams, S. Davis, and R. Spelman. 2012. Measuring residual feed intake in dairy heifers fed an alfalfa (Medicago sativa) cube diet. J. Dairy Sci. 95:1462-1471.

Wright, W., and A. Illius. 1995. A comparative study of the fracture properties of five grasses. Funct. Ecol. 9:269-278. 